Research Article

\title{
Design and Modeling of the Photonic Crystal Waveguide Structure for Heat-Assisted Magnetic Recording
}

\author{
Orrathai Watcharakitchakorn (iD) and Rardchawadee Silapunt $(\mathbb{D}$ \\ Department of Electronic and Telecommunication Engineering, King Mongkut's University of Technology Thonburi, Bangkok \\ 10140, Thailand \\ Correspondence should be addressed to Rardchawadee Silapunt; rardchawadee.sil@kmutt.ac.th
}

Received 7 December 2017; Accepted 10 January 2018; Published 28 February 2018

Academic Editor: Andres Sotelo

Copyright @ 2018 Orrathai Watcharakitchakorn and Rardchawadee Silapunt. This is an open access article distributed under the Creative Commons Attribution License, which permits unrestricted use, distribution, and reproduction in any medium, provided the original work is properly cited.

\begin{abstract}
The application of the photonic crystal (PC) waveguide (WG) as the light delivery system in the heat-assisted magnetic recording (HAMR) system is demonstrated. The structure consists of a $90^{\circ}$ bending PC waveguide and a ridge dielectric waveguide taper coupler. Three-dimensional (3D) models of structures are built and simulated in order to determine light coupling and transmission efficiencies. Geometric parameters including the taper length $\left(L_{\mathrm{TP}}\right)$, coupler inlet width $\left(W_{\mathrm{FW}}\right)$, and PC waveguide width $\left(W_{\mathrm{WG}}\right)$ are investigated. The initial simulation shows that the transmission efficiency of over $90 \%$ can be achieved with the coupler integrated with the straight PC waveguide. However, the overall transmission efficiency is substantially reduced to $53.8 \%$ when the coupler is attached to the $90^{\circ}$ bending PC waveguide. Our analysis shows that the wave mode matching and light decay rate in the waveguide cavity are significant contributing factors. The transmission efficiency increases to around $60.8 \%$ after some modification of the bending region.
\end{abstract}

\section{Introduction}

Photonic crystals (PCs) are periodical optical micro- and nanostructures that receive increasing attention due to their ability to manipulate light propagation while maintaining high transmission efficiency. They are typically designed based on their energy band gap to prohibit certain wavelengths. They can be arranged in one dimension (1D) [1, 2], two dimensions (2D) [3-5], and three dimensions (3D) depending on guiding requirements. The $2 \mathrm{D}$ PC structure is the most popular choice for optical devices and has found various applications such as integrated circuits (ICs), wave filters or multiplexers, and waveguides [6-13]. The PC's excellent transmission properties [14-16] and physical flexibility are attractive to minuscule WG fabrication. It can be bent to fit in a limited space and still achieve desirable performance $[14,15,17-19]$. A significant enhancement in operating bandwidth $[18,19]$ has also been reported.

Coupling is an important issue when it comes to the WG integration with other components of an optical communication device. Several taper PC coupling structures were investigated [20-23]. These studies agree on one common fact that the light propagation depends largely on the geometries of the coupler and guiding structure.

The capability of the PC to manipulate light as described above suggests the use of the PC structure as a potential candidate for light delivery in the heat-assisted magnetic recording (HAMR) system [24]. Several HAMR light delivery systems have been proposed, for example, the structure consisting of grating, slab waveguide, and near-field transducer (NFT) [24], the fiber optic connected with a spot-size converter (SSC) [25], and the butt-grating structure associated with multilayer core and cladding [26]. These proposed light deliveries, however, suffer from power losses at different locations and produce less than 50\% transmission efficiency.

In this paper, the photonic crystal waveguide for the light delivery in HAMR is demonstrated. The proposed structure shown in Figure 1 replaces the conventional structure [24] by combining grating, slab waveguide, and fixed curve mirror into a single piece through utilizing of coupling and bending sections. Note that the NFT is not included in the proposed design. The PC waveguide is attached at the front 


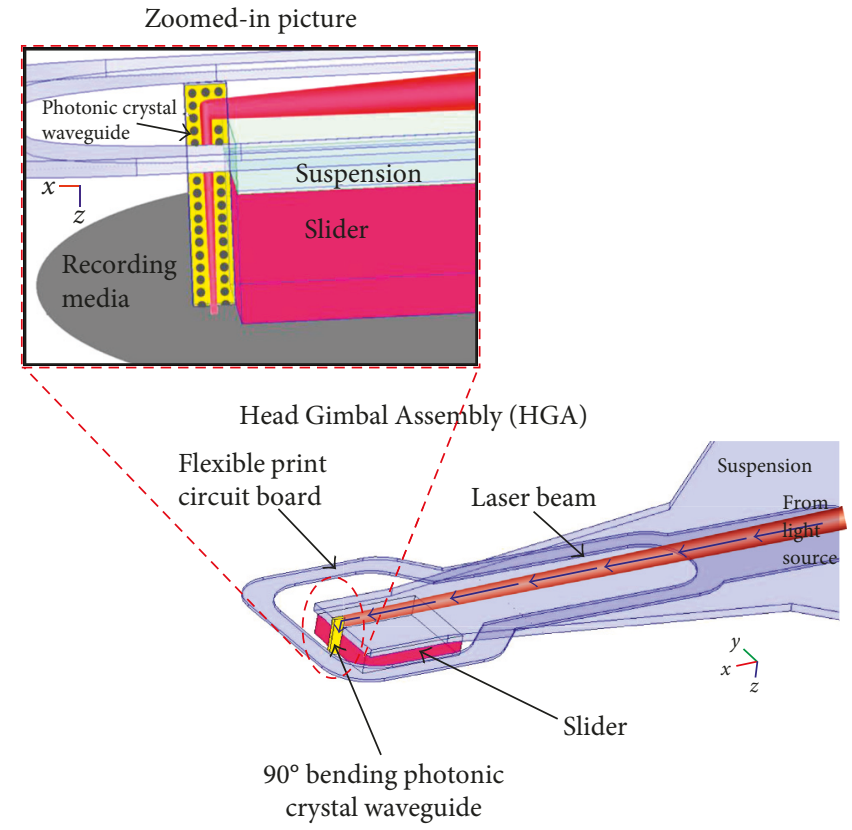

FIgURE 1: The proposed design of the HAMR light delivery system and light path.

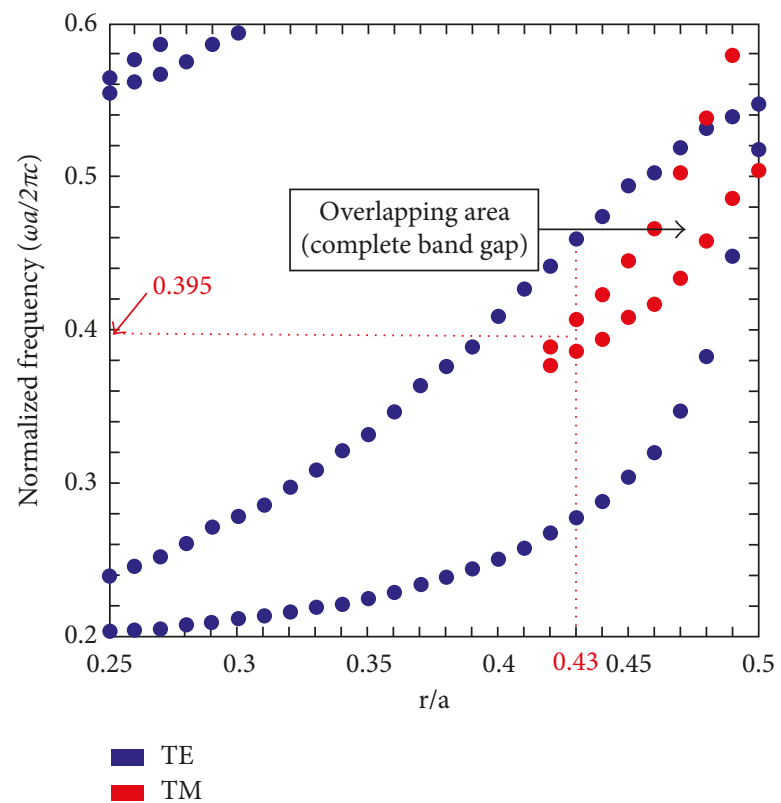

(a)

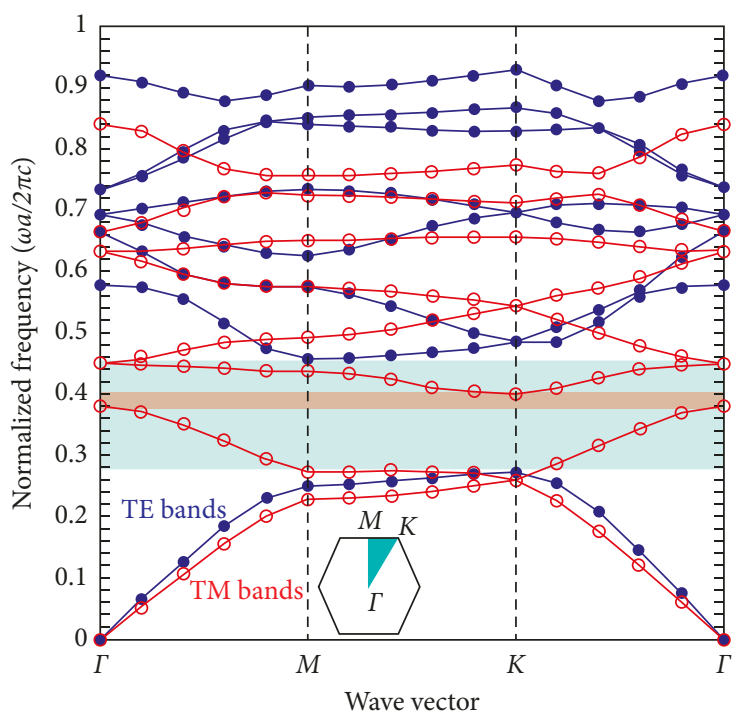

(b)

Figure 2: Gap map of the triangular lattice of air hole array in the p-Si substrate: (a) overall gap map and (b) photonic band structure related to the case $r / a=0.43$.

of the slider. The light path can be guided directly to the waveguide via the coupler at the inlet, and the fixed curve mirror is thus not required [24, 27, 28]. The light is then guided via a $90^{\circ}$ bend and propagates in the straight guiding section to the output.

The 3-dimensional (3D) design of the 2D PC waveguide is carried out using the basic Photonic Band Gap (PBG) software [29]. The modeling is performed with the widely used finite element method (FEM) simulator COMSOL
Multiphysics [30]. The performances of the waveguide including transmission and coupling efficiencies through bending and coupling sections are investigated.

\section{Photonic Band Gap (PBG)}

The $2 \mathrm{D}$ photonic crystal structure is the dielectric constant periodically modulated in two dimensions. In this paper, our PC waveguide is operated at $1,550 \mathrm{~nm}$ [31], and our PC 
waveguide is constructed using a $2 \mathrm{D}$ triangular lattice array of air holes embedded in polysilicon ( $\mathrm{p}-\mathrm{Si}$ ). At this wavelength, the frequency-dependent refractive index of $\mathrm{p}-\mathrm{Si}$ is 3.476 [9]. This structure is preferred since its band gap contains a larger overlapping area than other PC lattices and can be associated with both transverse electric (TE) and transverse magnetic (TM) modes. A simple laser source can thus be utilized without the need for a mode selector. Moreover, silicon has high refractive index and exhibits low loss at the wavelength of interest [32]. Note that if the NFT is included in the design, the waveguide must possess a certain polarization as most NFTs are polarization specific.

The PBG diagram is created by calculating each PBG, the forbidden wavelength range for propagation, associated with a specified ratio of air hole radius $(r)$ and lattice constant $(a)$. The consolidation of band gaps can be depicted by the gap map shown in Figure 2(a). The selected ratio of radius and lattice space constant $(r / a)$ is 0.43 , a relatively low value in the overlapping area known as the complete band [6]. A lower $r / a$ ratio is desirable in order to prevent structure collapse during fabrication. The calculated photonic band diagram of the lattice with $r / a=0.43$ is shown in Figure 2(b). In this figure, the normalized frequency is plotted versus the wave vector into the lattice $(\Gamma, M$, and $K)$. The calculations show that the band gap width is about $49.45 \%$ (from 0.276 to 0.458 ) for the TE mode and $5.12 \%$ (from 0.385 to 0.406 ) for the TM mode, respectively. An overlapping area with the center normalized frequency $(\omega a / 2 \pi c)$ is chosen at 0.395 .

The radius of the air hole $(r)$ and lattice space constant (a) are determined by the following relation:

$$
\text { Normalized frequency }=\frac{\omega a}{2 \pi c}=\frac{a}{\lambda},
$$

where $\omega$ is the angular frequency $(\mathrm{rad} / \mathrm{s}), c$ is the light velocity $(\mathrm{m} / \mathrm{s})$, and $\lambda$ is the wavelength $(\mathrm{m})$.

Therefore, the air hole radius $(r)$ and the lattice space constant $(a)$ are 263 and $612 \mathrm{~nm}$, respectively.

\section{Design and Modeling of the PC Waveguide for HAMR}

The PC waveguide is designed as a slab waveguide with coupling and bending sections. The 3D model and light path are shown in Figures 3 and 4, respectively. The coupling efficiencies associated with different coupling structures will be determined first. After the integration of the bending section, they will be reevaluated along with the transmission efficiencies.

The length of the PC waveguide is about $24.48(40 a) \mu \mathrm{m}$, and there are 21 rows in the air hole array. The PC guiding path is created by removing a center row. The slab thickness $(t)$ of the PC waveguide is chosen at $0.4 a$ or around $245 \mathrm{~nm}$. This thickness value is determined following the relation between the gap size and the PC thickness described in [33]. The taper section is formed by a conventional ridge dielectric slab waveguide whose thickness can be expressed as follows $[34,35]$ :

$$
h \approx \frac{\lambda}{2 n_{1}}
$$

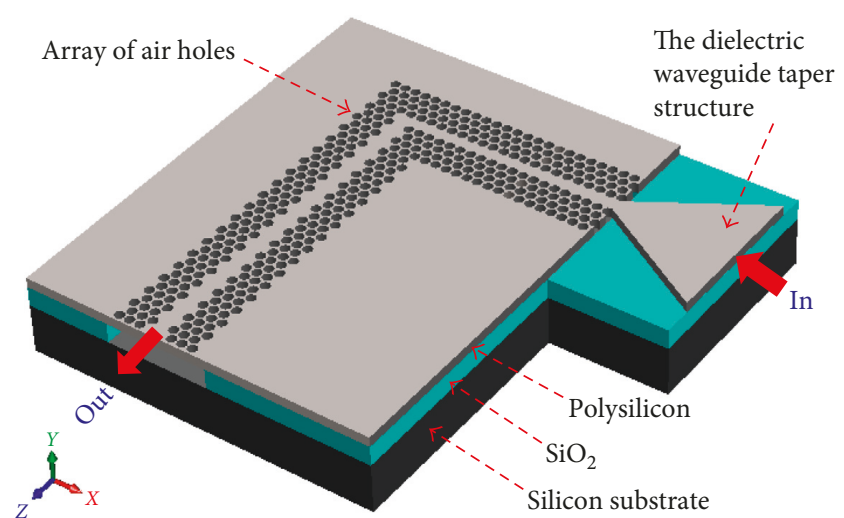

FIgure 3: The 3D model of the PC waveguide as the HAMR light delivery.

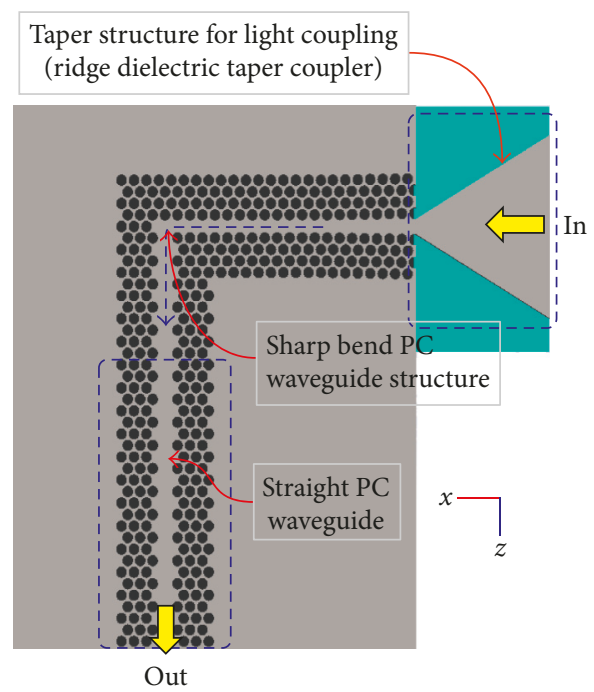

FIgUre 4: Top view of the 3D model of the PC waveguide as the HAMR light delivery.

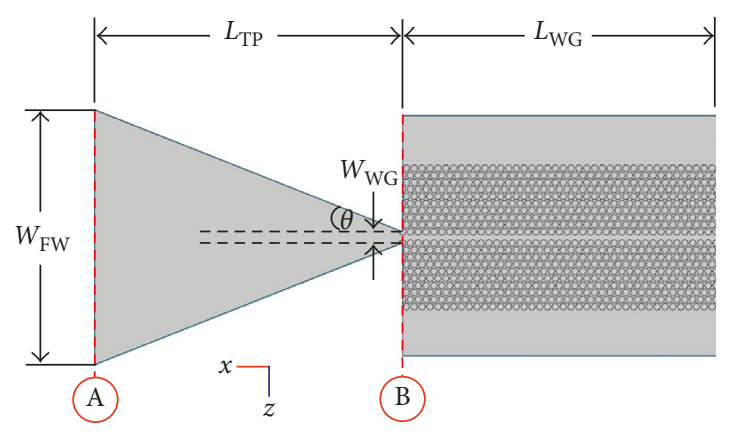

FIGURE 5: Design configuration of the dielectric waveguide taper coupler.

where $h$ is the dielectric taper slab thickness $(\mathrm{m})$ and $n_{1}$ is the core material (silicon) refractive index.

At the operating wavelength of $1,550 \mathrm{~nm}$, the thickness of the taper slab is around $245 \mathrm{~nm}(t / a=0.4)$, similar to the thickness of the PC slab. 

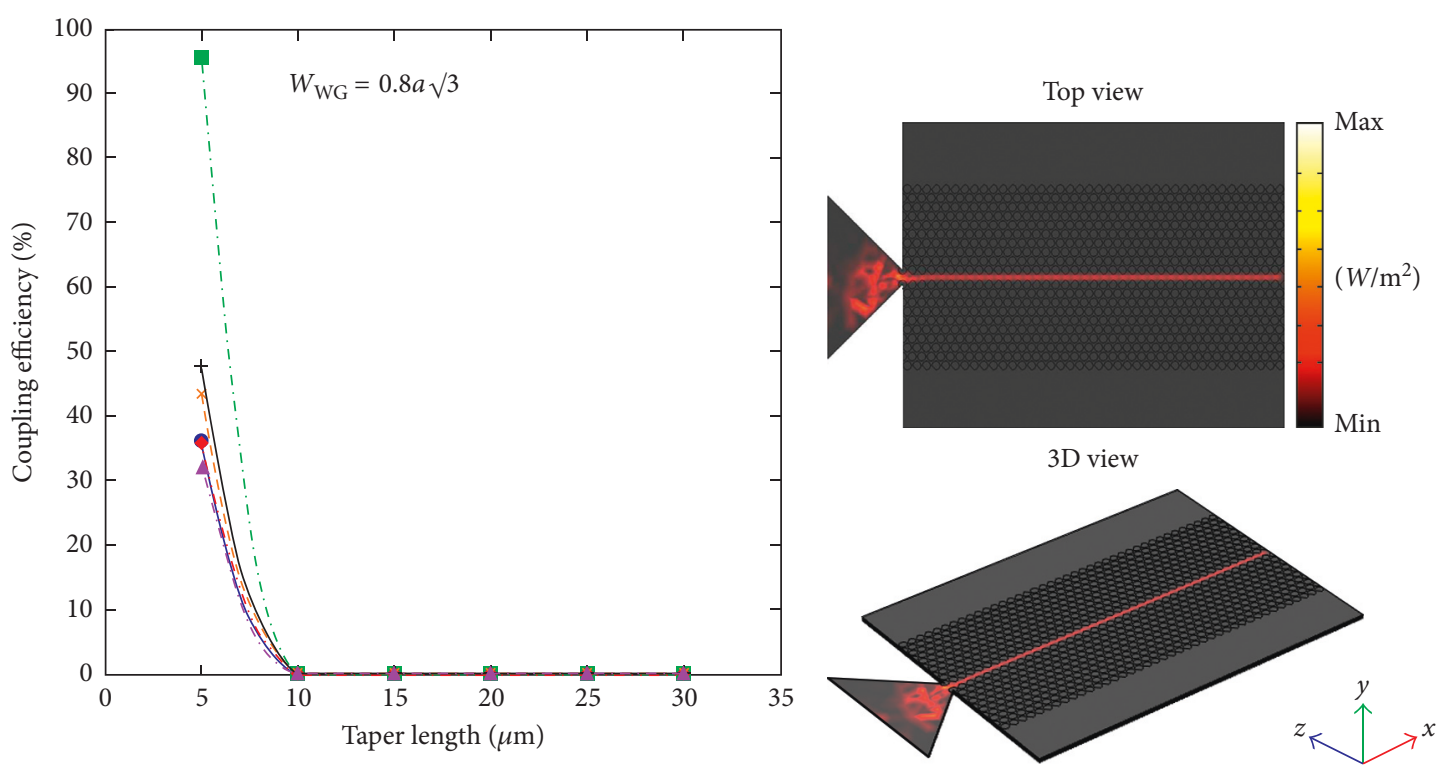

$$
\begin{aligned}
& \text { - } W_{\mathrm{FW}}=5 \mu \mathrm{m} \quad-*-W_{\mathrm{FW}}=20 \mu \mathrm{m} \\
& \begin{aligned}
-W_{\mathrm{FW}} & =10 \mu \mathrm{m} & \rightarrow & W_{\mathrm{FW}}=25 \mu \mathrm{m} \\
-W_{\mathrm{FW}} & =15 \mu \mathrm{m} & \rightarrow- & W_{\mathrm{FW}}=30 \mu \mathrm{m}
\end{aligned}
\end{aligned}
$$

$W_{\mathrm{FW}}=10 \mu \mathrm{m}$ and $L_{\mathrm{TP}}=5 \mu \mathrm{m}$

(a)
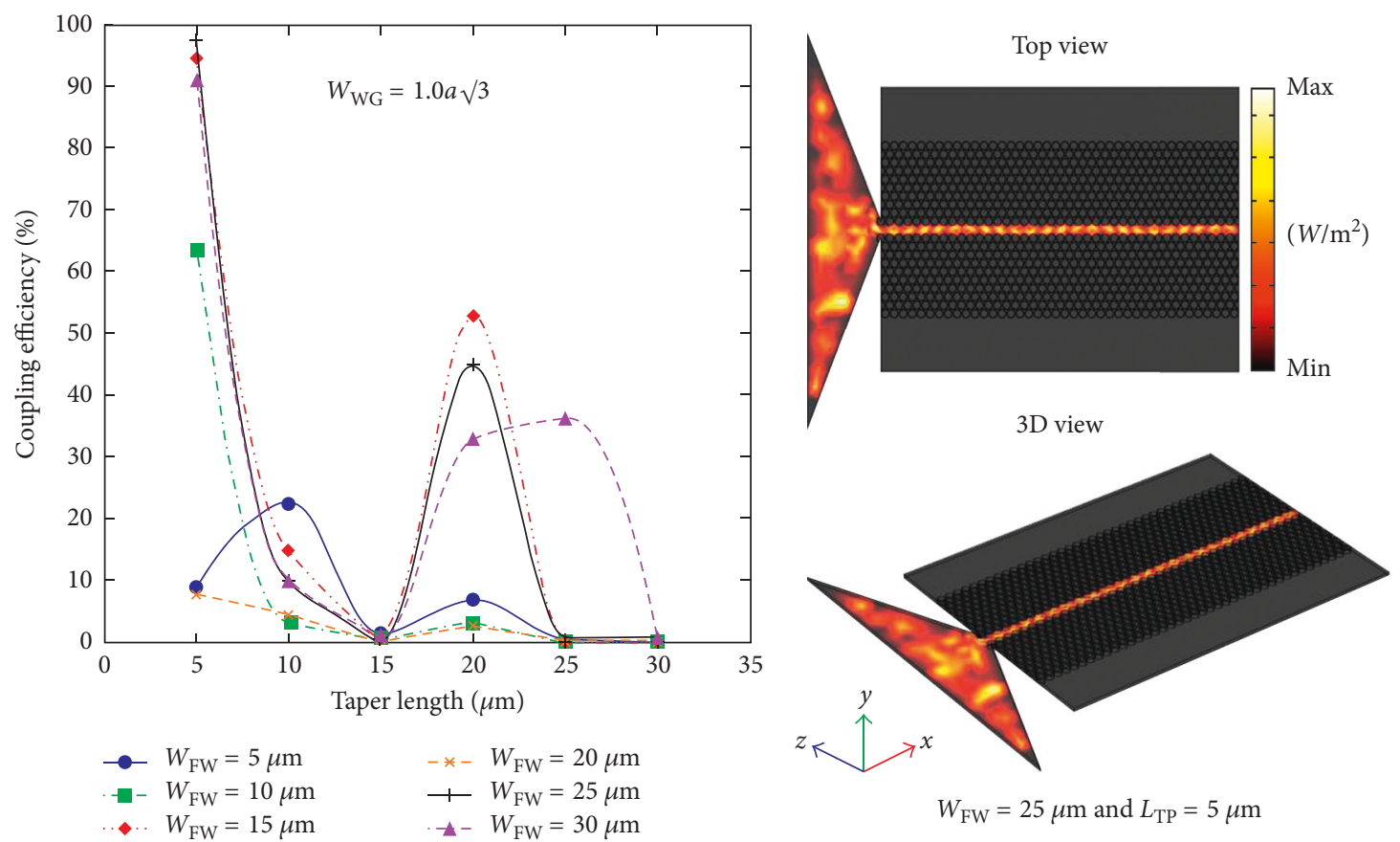

$W_{\mathrm{FW}}=25 \mu \mathrm{m}$ and $L_{\mathrm{TP}}=5 \mu \mathrm{m}$

(b)

FIGURE 6: Coupling efficiency for (a) $W_{\mathrm{WG}}=0.8 a \sqrt{ } 3$ and (b) $W_{\mathrm{WG}}=1.0 a \sqrt{ } 3$ for different inlet WG widths $\left(W_{\mathrm{FW}}\right)$.

3.1. Ridge Dielectric Taper Coupler Integrated with the Straight PC Waveguide Structure. We perform an initial simulation to observe light coupling into the straight $\mathrm{PC}$ waveguide from a ridge dielectric taper coupler shown in Figure 5. The taper coupler is an inlet width converter that is employed to convert the large inlet to the smaller one. The ridge dielectric waveguide taper structure, in particular, is simple and easy to fabricate [36].
The coupler inlet width $\left(W_{\mathrm{FW}}\right)$ and the taper length $\left(L_{\mathrm{TP}}\right)$ are varied from 5 to $30 \mu \mathrm{m}$. Note that the initial coupler inlet width of $5 \mu \mathrm{m}$ is selected based on the actual size of a typical fiber optic outlet. A parametric study is performed to observe the dependence of the coupling efficiency on the coupler inlet width $\left(W_{\mathrm{FW}}\right)$ and taper length $\left(L_{\mathrm{TP}}\right)$. Two sizes of the PC waveguide inlet width $\left(W_{\mathrm{WG}}\right)$ are considered which are $0.8 a \sqrt{ } 3$ and $1.0 a \sqrt{ } 3$ (about 0.848 and $1.060 \mu \mathrm{m}$ ). 
The former is selected to demonstrate the extreme case of coupling. The PC waveguide length $\left(L_{\mathrm{WG}}\right)$ is $24.48 \mu \mathrm{m}(40 a)$, and the waveguide slab thickness is $0.245 \mu \mathrm{m}(0.4 a)$. However, the computed power distribution is displayed as the net power. In order to accurately determine the coupling efficiency or the transmission efficiency over the coupler, values of incoming and reflected powers are needed. The coupling efficiency can be calculated from power density integration over the cross-sectional plane at the input $\left(P_{\text {in }}=P_{\text {source }}+P_{\text {reflection }}\right)$ and output $\left(P_{\text {out }}=P_{\text {transmission }}\right)$ ports of the coupler. The transmission $T$ is determined by $T=2 P_{\text {out }} /\left(P_{\text {in }}+P_{\text {out }}\right)=P_{\text {transmission }} / P_{\text {source}}$, whereby we assume $P_{\text {source }}=P_{\text {reflection }}+P_{\text {transmission }}$ [37]. $P_{\text {out }}$ is the surface integration of power densities over the cross-sectional plane at the output port (point $\mathrm{B}$ in Figure 5), and $P_{\text {in }}$ is the surface integration of power densities over the cross-sectional plane at the input port (point $A$ in Figure 5). The input power is set at $1 \mathrm{~mW}$ for convenience. Note that these formulas can be applied to any kind of waveguiding structures.

Figure 6 shows the coupling efficiency profiles with $W_{\text {WG }}$ equal to $0.8 a \sqrt{ } 3$ and $1.0 a \sqrt{ } 3$, respectively. It can be seen that the coupling efficiency decreases as the taper length increases. At $W_{\mathrm{WG}}=0.8 a \sqrt{ } 3$, the maximum efficiency of $95.3 \%$ is achieved with $W_{\mathrm{FW}}=10 \mu \mathrm{m}$ and $L_{\mathrm{TP}}=5 \mu \mathrm{m}$, as shown in Figure 6(a). The power density distribution associated with peak coupling efficiency is depicted on the right. The coupling efficiencies obtained from other structures are much lower and stay between 30 and $45 \%$.

The results are however different for $W_{\mathrm{WG}}=1.0 a \sqrt{ } 3$ as shown in Figure 6(b). It is observed that there are 3 structures that can achieve over $90 \%$ coupling efficiency, that is, $W_{\mathrm{FW}}=15 \mu \mathrm{m}$ and $L_{\mathrm{TP}}=5 \mu \mathrm{m}, W_{\mathrm{FW}}=25 \mu \mathrm{m}$ and $L_{\mathrm{TP}}=5 \mu \mathrm{m}$, and $W_{\mathrm{FW}}=30 \mu \mathrm{m}$ and $L_{\mathrm{TP}}=5 \mu \mathrm{m}$, respectively. The smaller the $L_{\mathrm{TP}}$, the better the coupler efficiency. At higher taper lengths, the bell-shaped profiles are observed. In our case, the good matching condition appears at smaller taper lengths. The power density distribution of the $W_{\mathrm{FW}}=25 \mu \mathrm{m}$ and $L_{\mathrm{TP}}=5 \mu \mathrm{m}$ structure is shown on the right of Figure 6(b). Compared to the $W_{\mathrm{WG}}=0.8 a \sqrt{ } 3$ PC structure, the $W_{\mathrm{WG}}=1.0 a \sqrt{ } 3$ structure provides better overall coupling efficiency. It is believed that a certain amount of power loss occurs from a reflection at the inlet of the PC waveguide. From the PC design standpoint, a bending section with a narrow inlet is difficult to construct. Therefore, the $W_{\mathrm{WG}}=1.0 a \sqrt{ } 3$ structure is selected for further study.

\subsection{Ridge Dielectric Taper Coupler Integrated with the} Bending PC Waveguide Structure. The ridge dielectric taper coupler is integrated with the $90^{\circ}$ bending PC slab waveguide to form the light delivery structure of HAMR as shown in Figure 7. The dimension of the $90^{\circ}$ bending PC slab waveguide includes $50 \mu \mathrm{m}$ of width $(w)$ and $55 \mu \mathrm{m}$ of length (l). Unfortunately, we cannot enlarge the waveguide dimension due to processing limitations. A number of periodic structures in the horizontal and vertical planes are 40 and 80 periods, respectively.

The transmission efficiencies are determined at 3 locations, shown as points B, C, and D in Figure 7. These efficiencies are defined by ratios of power flows at the locations

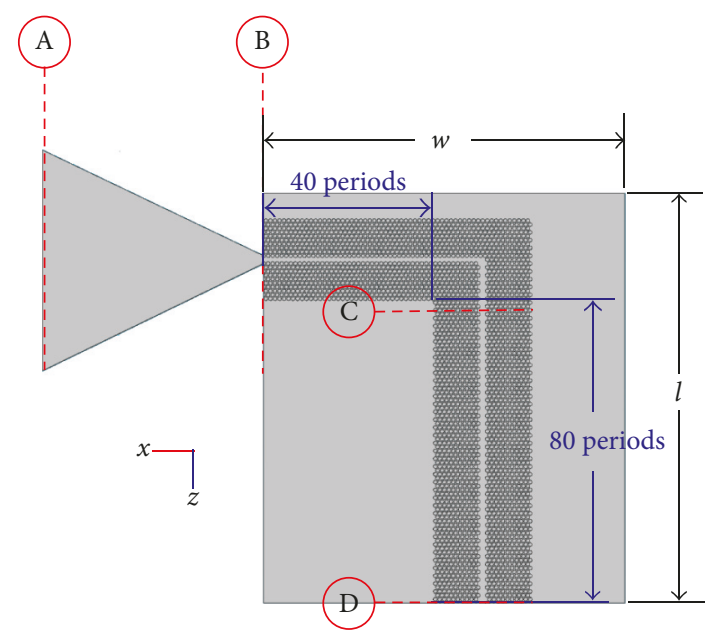

FIgURE 7: The PC light delivery model with locations defined for efficiency calculation.

of interest and powers at the inputs. The coupling efficiency, transmission efficiency after the bending section, and the overall waveguide transmission efficiency are expressed by

$$
\begin{aligned}
& \mathrm{CT}(\%)=\frac{\left(2 \times P_{\mathrm{B}}\right)}{\left(P_{\mathrm{B}}+P_{\mathrm{A}}\right)} \times 100, \\
& \mathrm{CB}(\%)=\frac{\left(2 \times P_{\mathrm{C}}\right)}{\left(P_{\mathrm{C}}+P_{\mathrm{A}}\right)} \times 100, \\
& \mathrm{CO}(\%)=\frac{\left(2 \times P_{\mathrm{D}}\right)}{\left(P_{\mathrm{D}}+P_{\mathrm{A}}\right)} \times 100 .
\end{aligned}
$$

Referring to Figure 7, $P_{\mathrm{A}}$ is the power over the crosssectional surface at point $\mathrm{A}$ (Watt), $P_{\mathrm{B}}$ is the power over the cross-sectional surface at point $\mathrm{B}$ (Watt), $P_{\mathrm{C}}$ is the power over the cross-sectional surface at point $C$ (Watt), and $P_{\mathrm{D}}$ is the power over the cross-sectional surface at point D (Watt).

Figure 8 (a) shows the plot of the taper coupling efficiency (CT) where $W_{\mathrm{FW}}$ is varied from 5 to $30 \mu \mathrm{m}$ and $L_{\mathrm{TP}}$ is varied from 2 to $30 \mu \mathrm{m}$. All structures exhibit bell-shaped efficiency profiles as a result of reflection and scattering in the guiding bodies at certain geometries. These findings indicate the strong dependence of the light transmission on the geometry. The highest CT of $97.2 \%$ is achieved with the $W_{\mathrm{FW}}=15 \mu \mathrm{m}$ and $L_{\mathrm{TP}}=5 \mu \mathrm{m}$ structure. However, the highest overall efficiency is achieved with the $W_{\mathrm{FW}}=5 \mu \mathrm{m}$ and $L_{\mathrm{TP}}=10 \mu \mathrm{m}$ structure. Figures $8(\mathrm{~b})$ and $8(\mathrm{c})$ show the plots of the bending transmission efficiency $(\mathrm{CB})$ and overall transmission efficiency (CO), respectively. We observe that, for every case, the efficiency decreases along the waveguide; moreover, it drops substantially after the bending section. The maximum overall efficiency is achieved at around $53.8 \%$ with the $W_{\mathrm{FW}}=5 \mu \mathrm{m}$ and $L_{\mathrm{TP}}=10 \mu \mathrm{m}$ structure.

The coupling behavior of the proposed structure is analyzed as follows. According to the coupled-mode theory [38], the wave mode profiles of the ridge dielectric taper waveguide and PC waveguide must be matched in order to optimize the transmission. Some researchers have reported 


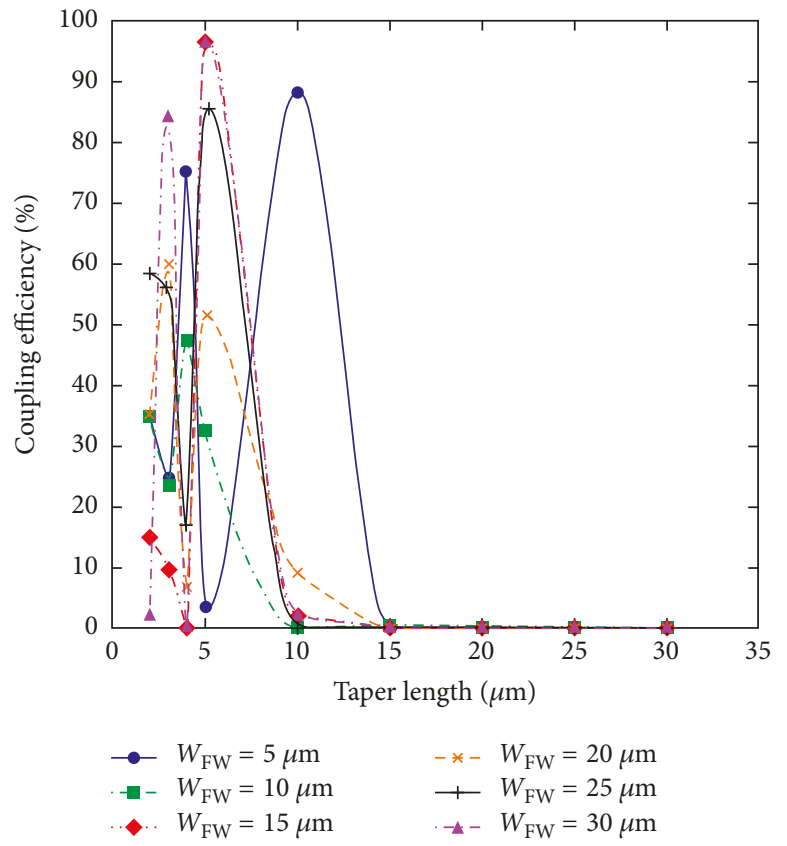

(a)

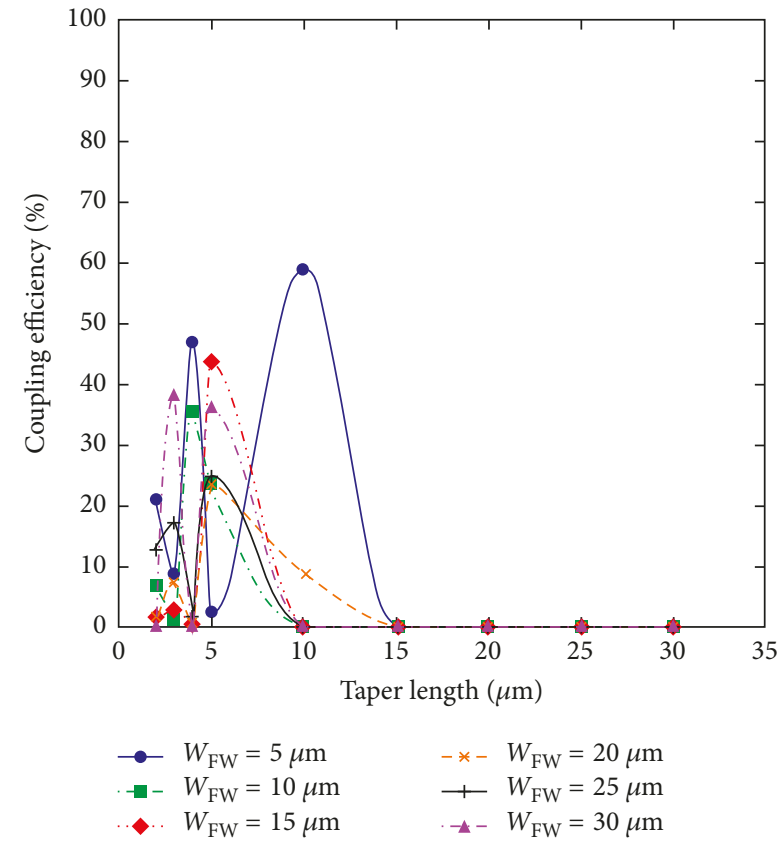

(b)

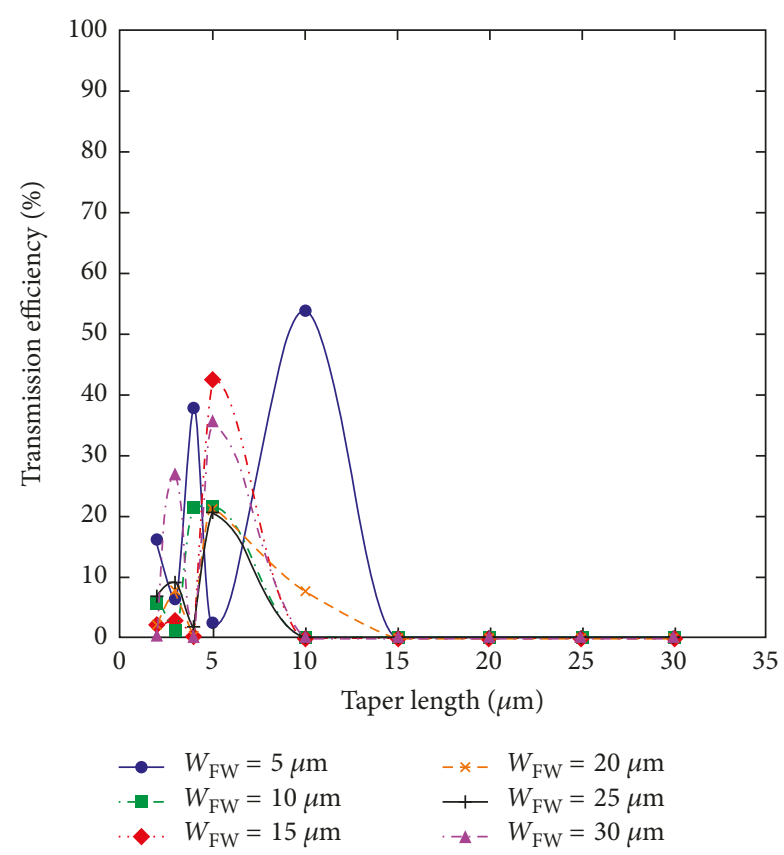

(c)

FIGURE 8: Coupling efficiency of (a) the coupler section, (b) transmission efficiency of the bending section, and (c) transmission efficiency of the entire structure.

applications of the taper waveguide as a wave mode converter [39-41]. We then calculate the wave mode profiles displayed in terms of electric field distributions of a single piece of the ridge dielectric taper waveguide with $W_{\mathrm{FW}}$ and $L_{\mathrm{TP}}$ both varying from 5 to $30 \mu \mathrm{m}$, with a $5 \mu \mathrm{m}$ increment, followed by those of a single-piece PC waveguide. Note that the wave mode profiles are determined at the outlet of the ridge taper waveguide and at the input of the PC waveguide.
Our results show that the number of wave mode profiles increases when $\mathrm{W}_{\mathrm{FW}}$ increases. The second-order wave mode profile of the $W_{\mathrm{FW}}=5 \mu \mathrm{m}$ structure is observed. In particular, we found that the wave mode at the output of the ridge taper waveguide with the $W_{\mathrm{FW}}=5 \mu \mathrm{m}$ and $L_{\mathrm{TP}}=10 \mu \mathrm{m}$ structure exhibits a strong match with that at the input of the PC waveguide, as shown in Figure 9. This result supports the highest value of coupling efficiency achieved for this particular structure. 

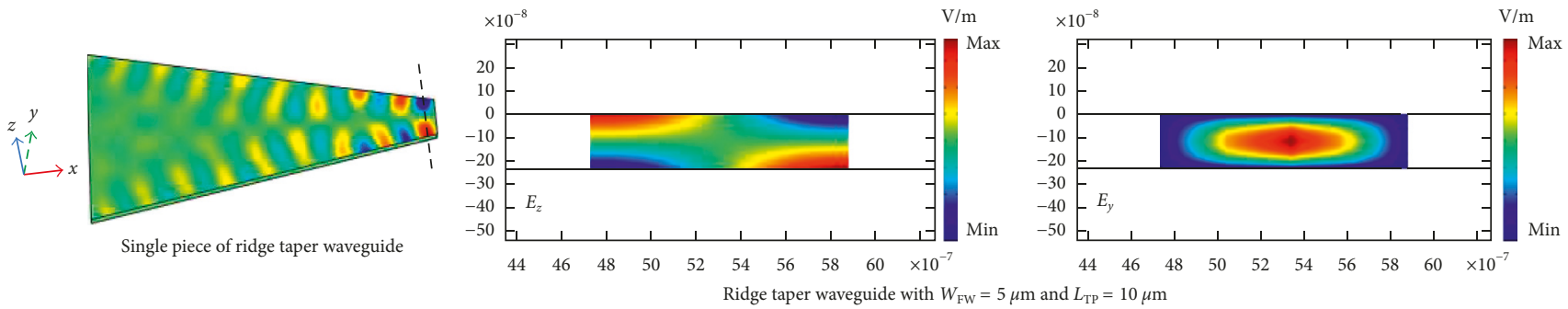

(a)
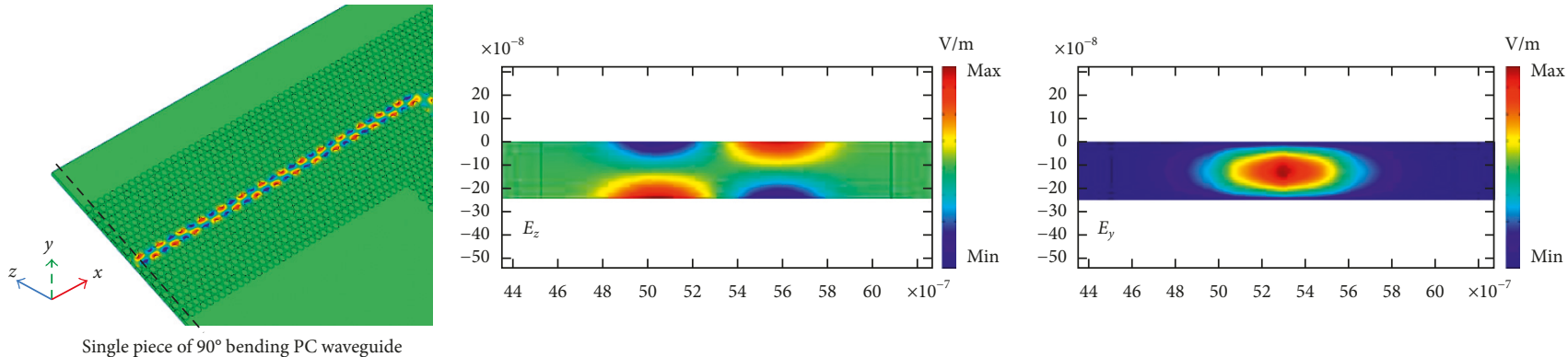

Single piece of $90^{\circ}$ bending PC waveguide

(b)

Figure 9: The wave mode profiles $\left(E_{z}\right.$ and $\left.E_{y}\right)$ at (a) the output of the ridge taper waveguide and (b) the input of the PC waveguide of the $W_{\mathrm{FW}}=5 \mu \mathrm{m}$ and $L_{\mathrm{TP}}=10 \mu \mathrm{m}$ structure.

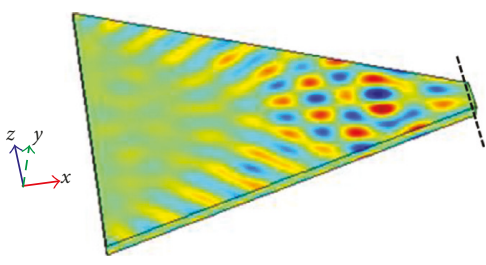

Single piece of ridge taper waveguide

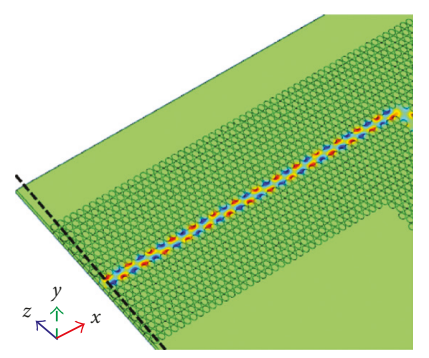

Single piece of $90^{\circ}$ bending PC waveguide

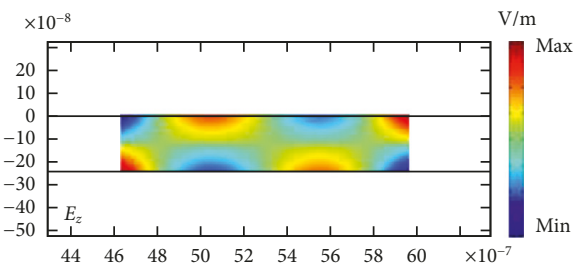

Ridge taper waveguide with $W_{\mathrm{FW}}=10 \mu \mathrm{m}$ and $L_{\mathrm{TP}}=10 \mu \mathrm{m}$

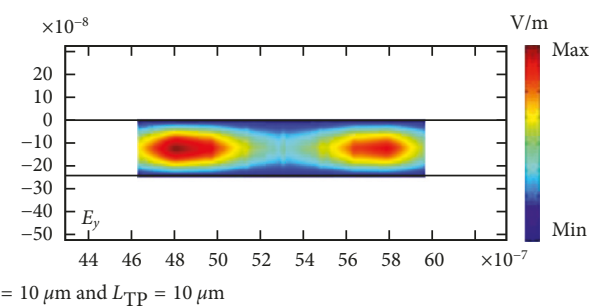

(a)
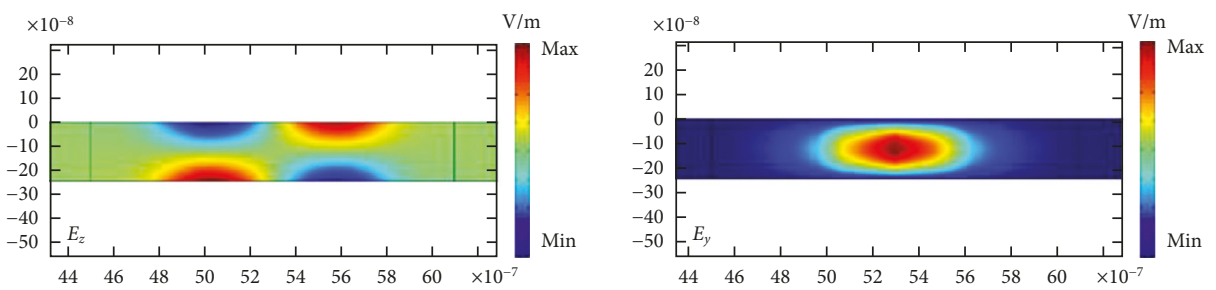

(b)

Figure 10: The electric field profiles $\left(E_{z}\right.$ and $E_{y}$ ) at (a) the output of the ridge taper waveguide and (b) the input of the PC waveguide of the $W_{\mathrm{FW}}=10 \mu \mathrm{m}$ and $L_{\mathrm{TP}}=10 \mu \mathrm{m}$ structure.

For comparison, an example of mismatched wave mode profiles is illustrated in Figure 10. This structure has $W_{\mathrm{FW}}=10 \mu \mathrm{m}$ and $L_{\mathrm{TP}}=10 \mu \mathrm{m}$. The wave mode profile at the output of the ridge taper waveguide is in the third order, while that at the input of the PC waveguide is in the second order. This could explain a nearly $0 \%$ efficiency obtained in the coupling section.
Although the matching wave modes between the ridge taper waveguide and PC waveguide can be obtained, power loss in the waveguide is still realized. The well-known concept of temporal coupled-mode theory [33, 42] is then applied to analyze the optical phenomena inside the light delivery structure. We construct the equivalent diagram of the light delivery structure as shown in Figure 11. 


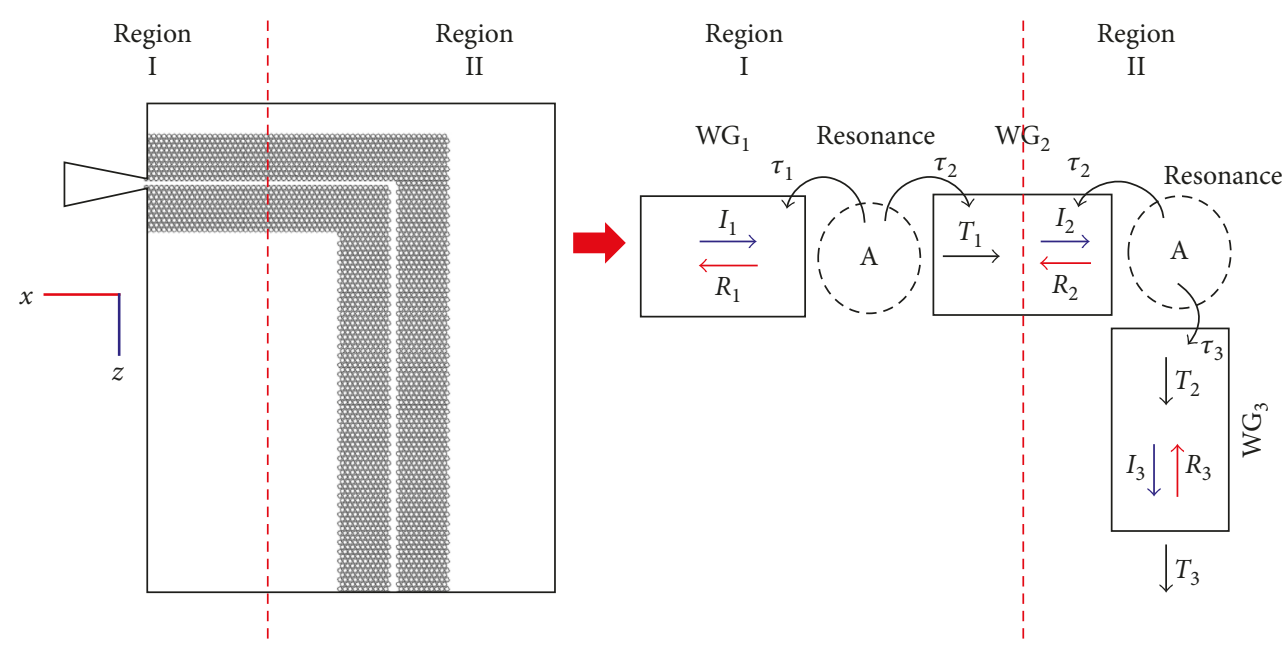

FIgURE 11: The equivalent diagram of the proposed light delivery structure.

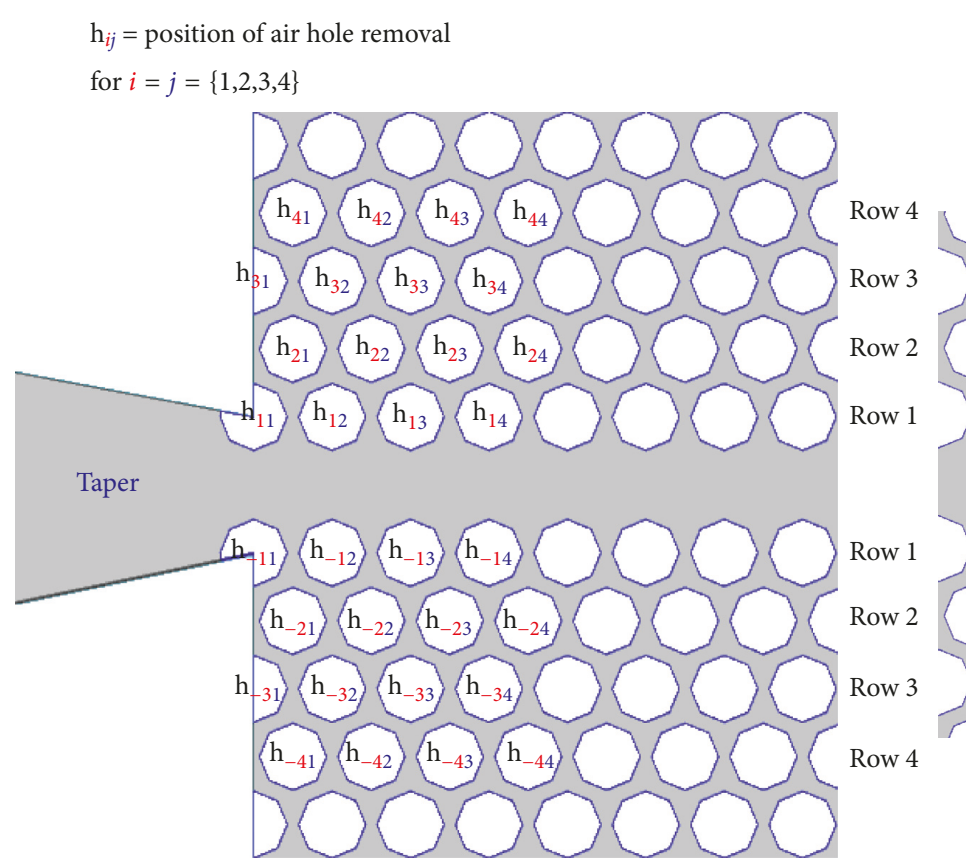

(a)

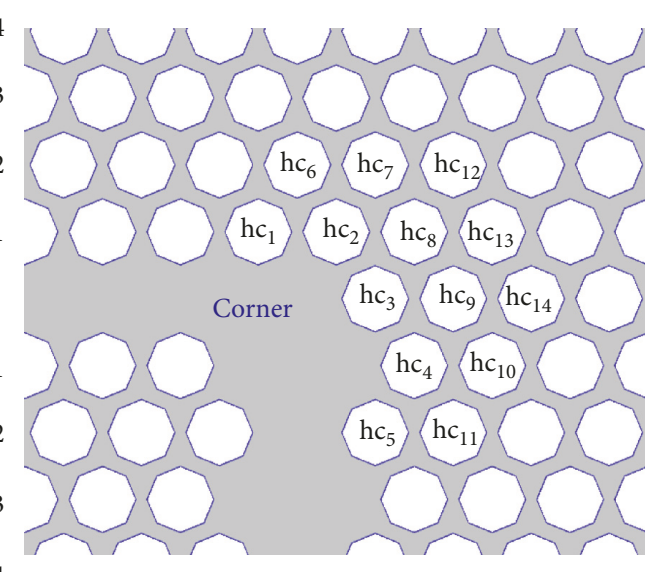

(b)

FIgURE 12: The air hole pattern removal at the (a) joint and (b) corner.

The light delivery structure can be separated into two regions. Region one is the ridge dielectric taper coupler waveguide $\left(\mathrm{WG}_{1}\right)$ connected with PC waveguide $\left(\mathrm{WG}_{2}\right)$. Region two is the horizontal PC waveguide $\left(\mathrm{WG}_{2}\right)$ connected with vertical PC waveguide $\left(\mathrm{WG}_{3}\right)$ to form a $90^{\circ}$ bending. Region one is considered first. When the light $\mathrm{I}_{1}$ reaches $\mathrm{WG}_{2}$, some part will be reflected and some will be radiated away due to the difference between $\mathrm{WG}_{1}$ and $\mathrm{WG}_{2}$. The reflected and transmitted waves in $\mathrm{WG}_{1}$ are denoted as $R_{1}$ and $T_{1}$, respectively.

According to the temporal coupled-mode theory, the cavity that connects $W_{1}$ and $W_{2}$ is considered as the resonator. Ideally, if the cavity resonates with a frequency $\left(\omega_{0}\right)$ equal to the operating frequency $(\omega)$ and light decays into $\mathrm{WG}_{1}$ and $\mathrm{WG}_{2}$ with equal lifetimes $\tau_{1}=\tau_{2}, 100 \%$ transmission can be achieved. Note that the resonant frequency and decay rate of the cavity-resonant mode strongly depend on geometry $[33,43,44]$. Therefore, the geometry of the cavity should be modified to increase the coupling between $W G_{1}$ and $\mathrm{WG}_{2}$. For region two, another cavity is formed between $\mathrm{WG}_{2}$ and $\mathrm{WG}_{3}$. Again, to achieve $100 \%$ transmission efficiency over this section, the abovementioned conditions must be applied.

The improvement of cavity matching is then demonstrated here. Several modifying patterns of the $W_{\mathrm{FW}}=5 \mu \mathrm{m}$ and $L_{\mathrm{TP}}=10 \mu \mathrm{m}$ structure are created by randomly removing some air holes near the joint and corner. Figure 12(a) shows the location of air hole removal, where $\mathrm{h}_{i j}$ is the coordinate of removed hole position at the joint between the taper and PC 


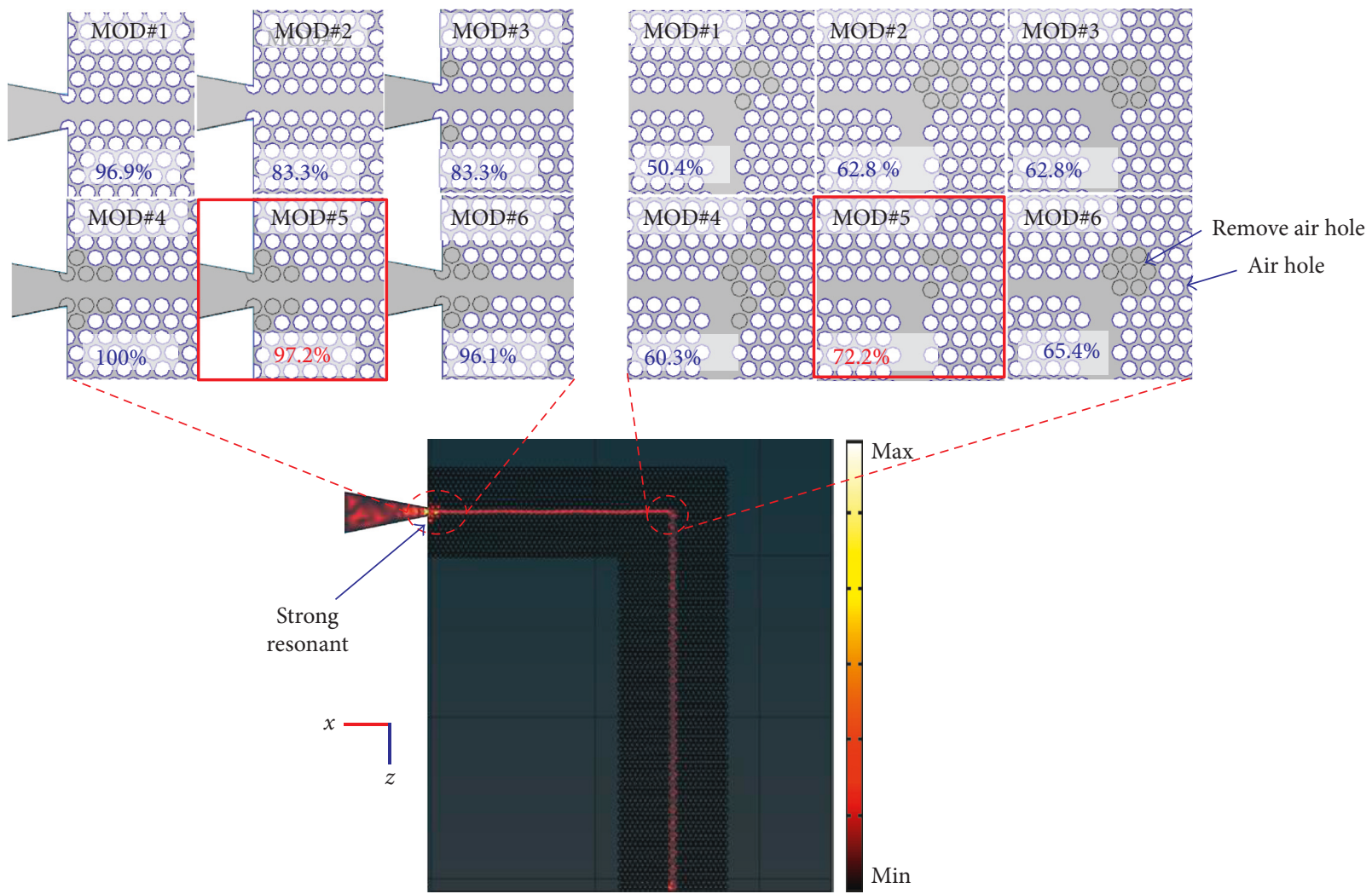

FIGURE 13: Modifying pattern 5 (MOD\#5) provides the highest transmission efficiency.

waveguide for $i=j=\{1,2,3,4\}$. The location of removed air holes around the corner is depicted in Figure 12(b). More than 30 cases are run, and the six best cases are selected and shown in Figure 13. The coupling and bending transmission efficiencies are displayed in the figure.

It can be seen that the coupling and bending transmission efficiencies of the PC waveguide structure can actually be improved when joints and corners are modified. In our 6 best cases, MOD\#5 provides the highest efficiency. Specifically, CT, CB, and CO increase from $88.6 \%$ to $97.2 \%$, $59.8 \%$ to $72.2 \%$, and $53.8 \%$ to $60.8 \%$, respectively. Note that the obtained overall transmission efficiency from the MOD\#5 case is better than those reported previously [24-26]. To further improve the transmission efficiency, a systematic approach should be implemented. In addition, deformation of some air holes might be necessary [13].

Finally, the hotspot size at the output facet of the $W_{\mathrm{FW}}=5 \mu \mathrm{m}$ and $L_{\mathrm{TP}}=10 \mu \mathrm{m}$ structure is determined. The power distribution at the output facet of the structure is shown in Figure 14. By considering the full width half maximum (FWHM) of the power distribution profile, we obtain a spot size of about $103 \mathrm{~nm} \times 413 \mathrm{~nm}$. This spot size is still too large for high areal density recording. More alteration of air holes near the output or NFT integration is recommended for further confinement of the spot size.

\section{Conclusions}

This paper investigates a PC waveguide-based light delivery system for HAMR. We examined taper coupling and bending structures. The PC waveguide model is created by removing a single row of photonic crystals in a triangular lattice array of air holes in the silicon substrate. The PC waveguide operates at $1,550 \mathrm{~nm}$ and can accommodate both TM- and TE-polarized sources. The lattice space $(a)$ and air hole radius $(r)$ are 612 and $263 \mathrm{~nm}$, respectively. The dielectric coupler model is designed by varying the inlet waveguide width $\left(W_{\mathrm{FW}}\right)$ and the taper length $\left(L_{\mathrm{TP}}\right)$ from 5 to $30 \mu \mathrm{m}$. The PC waveguide widths of interest are $0.8 a \sqrt{ } 3$ or $0.848 \mu \mathrm{m}$ and $1.0 a \sqrt{ } 3$ or $1.060 \mu \mathrm{m}$. The dielectric taper coupler integrated with the straight PC waveguide structure shows the highest coupling efficiency of $95.3 \%$ with the $W_{\mathrm{FW}}=10 \mu \mathrm{m}, L_{\mathrm{TP}}=5 \mu \mathrm{m}$, and $W_{\mathrm{WG}}=0.8 a \sqrt{ } 3 \mu \mathrm{m}$ structure. For $W_{\mathrm{WG}}=1.0 a \sqrt{ } 3 \mu \mathrm{m}$, there are 3 structures with $L_{\mathrm{TP}}=5 \mu \mathrm{m}$ that achieve over $90 \%$ coupling efficiency, that is, $94.6 \%$ for $W_{\mathrm{FW}}=15 \mu \mathrm{m}, 97.4 \%$ for $W_{\mathrm{FW}}=25 \mu \mathrm{m}$, and $90.8 \%$ for $W_{\mathrm{FW}}=30 \mu \mathrm{m}$. The $1.0 \mathrm{a} \sqrt{ } 3 \mu \mathrm{m}$ width is chosen for integration with the $90^{\circ}$ bending structure to form the proposed light delivery structure since it provides larger guiding area at the bending section.

The coupling efficiencies of most structures drop slightly after attaching the bending structures. The overall highest CT is achieved at $L_{\mathrm{TP}}=5 \mu \mathrm{m}$. The bell-shaped profiles are observed in every case of $W_{\mathrm{FW}}$. These results indicate that the effects of light reflection and scattering are altered in different guiding geometries, and the optimization of waveguide geometry is necessary. The transmission efficiency apparently decreases along the waveguide. The maximum overall efficiency of around $\mathrm{CO}=53.8 \%$ is achieved with the $W_{\mathrm{FW}}=5 \mu \mathrm{m}$ and $L_{\mathrm{TP}}=10 \mu \mathrm{m}$ structure. 

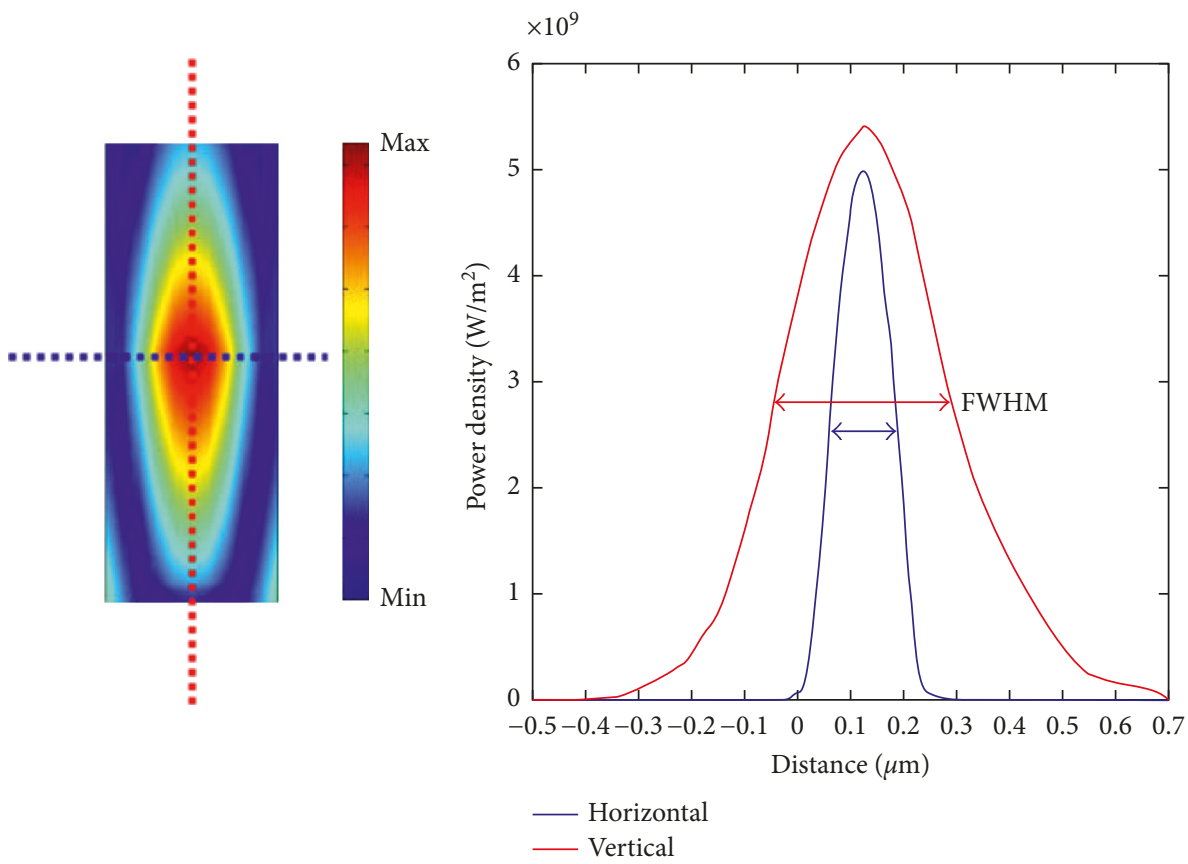

Figure 14: Power distribution at the end facet of the entire model.

Different dimensions of the ridge dielectric coupler taper waveguides produce varied output wave modes that affect the matching to the PC waveguide. Modification of air holes at the joint and corner of the PC waveguide of the $W_{\mathrm{FW}}=5 \mu \mathrm{m}$ and $L_{\mathrm{TP}}=10 \mu \mathrm{m}$ structure appears to improve the efficiencies at the taper coupler section and the overall structure. The optimal coupling and overall transmission efficiencies increase to $97.2 \%$ and $60.8 \%$, respectively. These efficiency levels are definitely sufficient, considering our simple design and fabrication [36]. In addition, the value of the overall transmission efficiency is better than those reported previously. The PC waveguide is therefore a promising candidate for the HAMR light delivery system. However, more alteration of air holes near the output or NFT integration is recommended to further confine the spot size.

\section{Conflicts of Interest}

The authors declare that they have no conflicts of interest.

\section{Acknowledgments}

The authors would like to thank King Mongkut's University of Technology Thonburi and Seagate Technology (Thailand) Co., Ltd., for supporting this work. In addition, the authors would like to acknowledge the financial support to this work received from the NSTDA University Industrial Research Collaboration (NUI-RC) and National Science and Technology Development Agency.

\section{References}

[1] R. H. Lipson and C. Lu, "Photonic crystals: a unique partnership between light and matter," European Journal of Physics, vol. 30, no. 4, pp. S33-S38, 2009.
[2] C.-J. Wu and Z.-H. Wang, "Properties of defect modes in onedimensional photonic crystals," Progress in Electromagnetics Research, vol. 103, pp. 169-184, 2010.

[3] I. Andonegui and A. J. Garcia-Adeva, "The finite element method applied to the study of two-dimensional photonic crystals and resonant cavities," Optics Express, vol. 21, no. 4, pp. 4072-4092, 2013.

[4] X. Gan, Y. Gao, K. F. Mak et al., "Controlling the spontaneous emission rate of monolayer $\mathrm{MoS}_{2}$ in a photonic crystal nanocavity," Applied Physics Letters, vol. 103, no. 18, p. 181119, 2013.

[5] H. Li and X. Yang, "Larger absolute band gaps in twodimensional photonic crystals fabricated by a three-ordereffect method," Progress in Electromagnetics Research, vol. 108, pp. 385-400, 2010.

[6] C. Jamois, R. B. Wehrspohn, L. C. Andreani, C. Herrmann, O. Hess, and U. Gosele, "Silicon-based two-dimensional photonic crystal waveguides," Photonics and NanostructuresFundamentals and Applications, vol. 1, no. 1, pp. 1-13, 2003.

[7] S. Meister, B. Franke, H. J. Eichler et al., "Photonic integrated circuits for optical communication," Optik \& Photonik, vol. 7, no. 2, pp. 59-62, 2012.

[8] T. Niemi, L. H. Frandsen, K. K. Hede, A. Harpoth, P. I. Borel, and M. Kristensen, "Wavelength-division demultiplexing using photonic crystal waveguides," IEEE Photonics Technology Letters, vol. 18, no. 1, pp. 226-228, 2006.

[9] A. Blanco-Redondo, P. Sarriugarte., A. Garcia-Adeva, J. Zubia, and R. Hillenbrand, "Coupling mid-infrared light from a photonic crystal waveguide to metallic transmission lines," Applied Physics Letters, vol. 104, no. 1, p. 011105 , 2014.

[10] D. C. Tee, T. Kambayashi, S. R. Sandoghchi, N. Tamchek, and F. R. M. Adikan, "Efficient, wide angle, structure tuned $1 \$$, times $\backslash \$ 3$ photonic crystal power splitter at $1550 \mathrm{~nm}$ for triple play applications," Journal of Lightwave Technology, vol. 30, no. 17, pp. 2818-2823, 2012. 
[11] Y.-D. Wu, "New design of all-optical slow light tdm structure based on photonic crystals," Progress in Electromagnetics Research, vol. 146, pp. 89-97, 2014.

[12] P. I. Borel, L. H. Frandsen, L. J. Burgos, T. Niemi, and A. Lavrinenko, "Optimization and applications of planar silicon-based photonic crystal devices," Proceedings of SPIE, vol. 6014, pp. 1-9, 2005.

[13] Y. Shi, "A compact polarization beam splitter based on a multimode photonic crystal waveguide with an internal photonic crystal section," Progress in Electromagnetics Research, vol. 103, pp. 393-401, 2010.

[14] M. Attila, J. C. Chen, I. Kurland, S. Fan, R. V. Pierre, and J. D. Joannopoulos, "High transmission through sharp bends in photonic crystal waveguides," Physical Review Letters, vol. 77, no. 18, pp. 3787-3790, 1996.

[15] K. Rauscher, D. Erni, J. Smajic, and C. Hafner,, "Improved transmission for $60^{\circ}$ photonic crystal waveguide bends," in Proceedings of Progress in Electromagnetics Research, pp. 2528, Pisa, Italy, March 2004.

[16] I. Andonegui, I. Calvo, and A. J. Garcia-Adeva, "Inverse design and topology optimization of novel photonic crystal broadband passive devices for photonic integrated circuits," Applied Physics A, vol. 115, no. 2, pp. 433-438, 2014.

[17] O. Watcharakitchakorn and R. Silapunt, "Optical field enhancement for heat-assisted magnetic recording system using photonic crystal waveguide," in Proceedings of the 2012 International Conference on Electromagnetics in Advanced Applications, pp. 442-445, Cape Town, South Africa, September 2012.

[18] P. I. Borel, L. H. Frandsen, A. Harpth et al., "Bandwidth engineering of photonic crystal waveguide bends," Electronics Letters, vol. 40, no. 20, pp. 1263-1264, 2004.

[19] M. K. Moghaddam, M. M. Mirsalehi, and A. R. Attari, “A $60^{\circ}$ photonic crystal waveguide bend with improved transmission characteristics," Optica Applicata, vol. 39, pp. 307-317, 2009.

[20] A. A. M. Kok, R. Meneghelli, J. J. G. M. van der Tol, and M. K. Smit, "Efficient coupling structures for integration of pillar photonic crystals with ridge waveguides," in Proceedings of the 11th Annual Symposium of the IEEE/LEOS Benelux Chapter, pp. 37-40, Eindhoven, Netherlands, NovemberDecember 2006.

[21] H. T. Chien, C. Lee, H. K. Chiu et al., "The comparison between the graded photonic crystal coupler and various couplers," Journal of Lightwave Technology, vol. 27, no. 14, pp. 2570-2574, 2009.

[22] P. Pottier, M. Gnan, and R. M. De La Rue, "Efficient coupling into slow-light photonic crystal channel guides using photonic crystal tapers," Optics Express, vol. 15, no. 11, pp. 6569-6576, 2007.

[23] H. Andrea, S. Pablo, J. Sanchez-Dehesa, and M. Javier, "Highefficiency defect-based photonic-crystal tapers designed by a genetic algorithm," Journal of Lightwave Technology, vol. 23, no. 11, pp. 3881-3888, 2005.

[24] M. H. Kryder, E. C. Gage, T. W. McDaniel et al., "Heat assisted magnetic recording," Proceedings of the IEEE, vol. 96, no. 11, pp. 1810-1835, 2008.

[25] M. Hirata, S. Tanabe, M. Oumi et al., "Light delivery system for heat-assisted magnetic recording," IEEE Transactions on Magnetics, vol. 45, no. 11, pp. 5016-5021, 2009.

[26] S. Hasegawa, F. Tawa, and W. Odajima, "Optical head with metal cladding in asymmetrical butted-grating structure for small thermal spot in laser-assisted magnetic recording," Optical Review, vol. 17, no. 5, pp. 486-494, 2010.
[27] W. A. Challener, C. Peng, A. V. Itagi et al., "Heat-assisted magnetic recording by a near-field transducer with efficient optical energy transfer," Nature Photonics, vol. 3, no. 4, pp. 220-224, 2009.

[28] W. A. Challener, C. Mihalcea, C. Peng, and K. Pelhos, "Miniature planar solid immersion mirror with focused spot less than a quarter wavelength," Optics Express, vol. 13, no. 18, pp. 7189-7197, 2005.

[29] S. G. Johnson, "MIT photonic bands," http://jdj.mit.edu/wiki/ index.php?title=MIT_Photonic_Bands\&printable=yes.

[30] COMSOL, COMSOL Multiphysics User's Guide \& COMSOL Multiphysics Modeling Guide, COMSOL, Stockholm, Sweden, 4.3b edition, http://www.comsol.com.

[31] K. Preston and M. Lipson, "Slot waveguides with polycrystalline silicon for electrical injection," Optics Express, vol. 17, no. 3, pp. 1527-1534, 2009.

[32] H. Butt, Q. Dai, T. D. Wilkinson, and G. A. J. Amaratunga, "Photonic crystals \& metamaterial filters based on $2 \mathrm{~d}$ arrays of silicon nanopillars," Progress in Electromagnetics Research, vol. 113, pp. 179-194, 2011.

[33] J. D. Joannopoulos, S. G. Johnson, R. D. Meade, and J. N. Winn, Photonic Crystals: Molding the Flow of Light, Princeton University Press, Princeton, NJ, USA, 2nd edition, 2008.

[34] R. R. A. Syms and J. R. Cozens, Optical Guided Waves and Devices, Chapter 6, McGraw-Hill Companies, Berkshire, UK, 1st edition, 1992.

[35] R. G. Hunsperger, Integrated Optics: Theory and Technology, Springer, Berlin, Germany, 6th edition, 2009.

[36] O. Watcharakitchakorn, R. Silapunt, and M. Charlton, "A study of poly-silicon and $\mathrm{Ta} 2 \mathrm{O} 5$ photonic crystal waveguides for HAMR light delivery system," in Proceedings of the TENCON 2015-2015 IEEE Region 10 Conference, pp. 1-4, Macao, China, November 2015.

[37] P. Strasser, G. Stark, F. Robin et al., "Optimization of a $60^{\circ}$ waveguide bend in InP-based 2D planar photonic crystals," Journal of the Optical Society of America B, vol. 25, no. 1, pp. 67-73, 2008.

[38] R. Baets and G. Roelkens, Fotonica-Photonics, Lecture Notes of the Academic Year 2009-2010 Chapter 5, in Dielectric Waveguides, Universiteit Gent, Ghent, Belgium, http://fotonica.intec. ugent.be/download/ocs131.pdf.

[39] D. Dai, Y. Tang, and J. Bowers, "Mode conversion in tapered submicron silicon ridge optical waveguides," Optics Express, vol. 20, no. 12, pp. 13425-13439, 2012.

[40] D. Vermeulen, K. Y. Acoleyen, S. Ghosh et al., "Efficient tapering to the fundamental Quasi-TM mode in asymmetrical waveguides," in Proceedings Of the European Conference on Integrated Optics, pp. 7-9, University of Cambridge, Cambridge, UK, April 2010.

[41] J. H. Schmid, B. Lamontagne, P. Cheben et al., "Mode converters for coupling to high aspect ratio silicon-on-insulator channel waveguides," IEEE Photonics Technology Letters, vol. 19, pp. 855-857, 2007.

[42] H. A. Haus, "Waves and fields in optoelectronics," in PrenticeHall series in Solid State Physical Electronics, N. Holonyak, Ed., pp. 197-234, Prentice-Hall, Englewood Cliffs, NJ, USA, 1984.

[43] C. Manolatou, S. G. Johnson, S. Fan, P. R. Villeneuve, H. A. Haus, and J. D. Joannopoulos, "High-density integrated optics," Journal of Lightwave Technology, vol. 17, no. 9, pp. 1682-1692, 1999.

[44] S. Fan, S. G. Johnson, J. D. Joannopoulos, C. Manolatou, and H. A. Haus, "Waveguide branches in photonic crystals," Journal of the Optical Society of America B, vol. 18, pp. 162-165, 2001. 


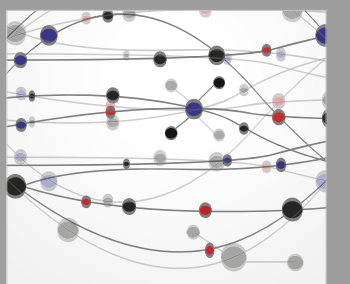

The Scientific World Journal
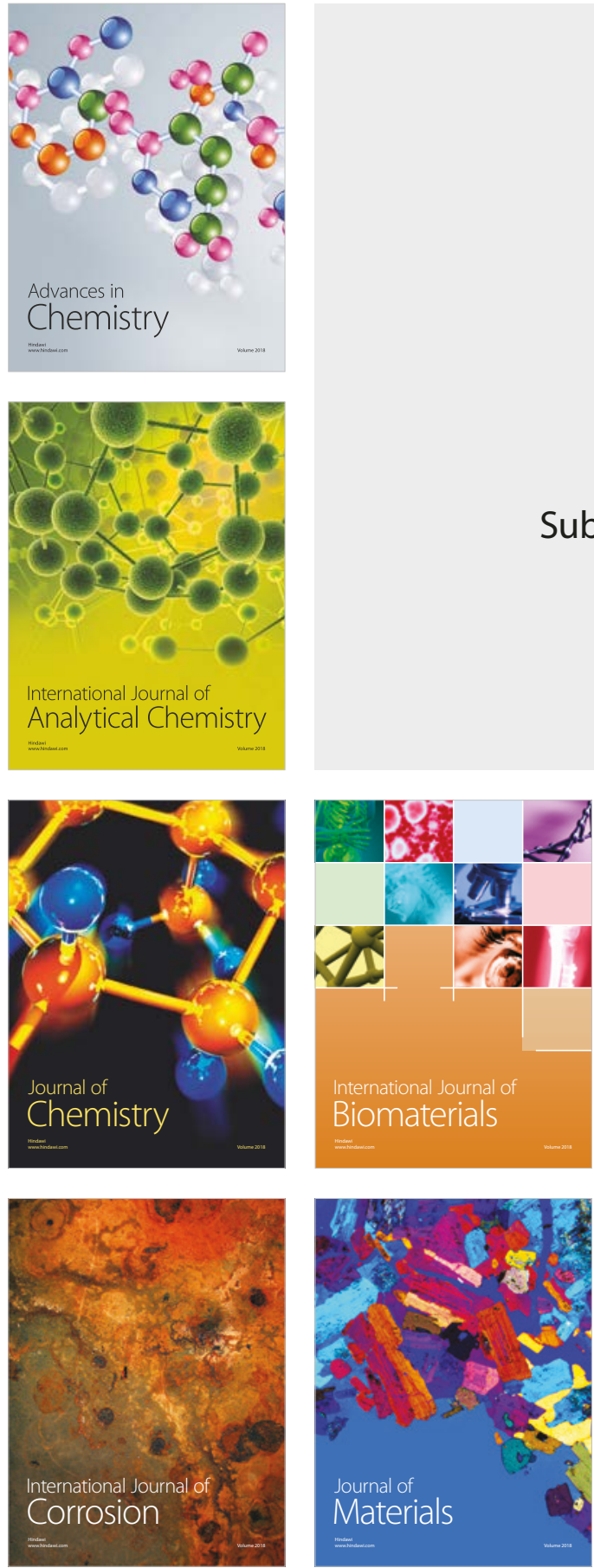

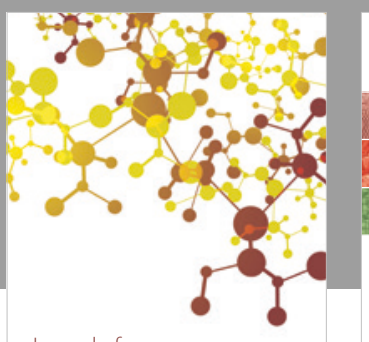

Journal of

Applied Chemistry
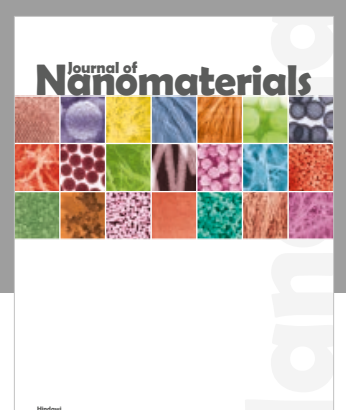

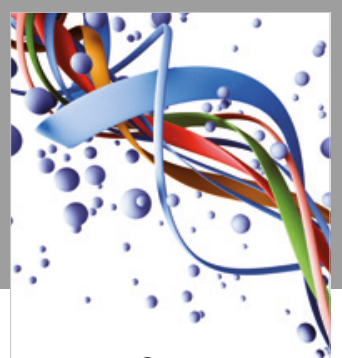

Scientifica

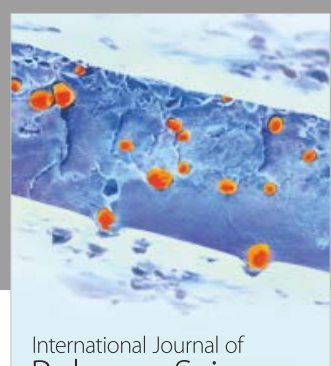

Polymer Science

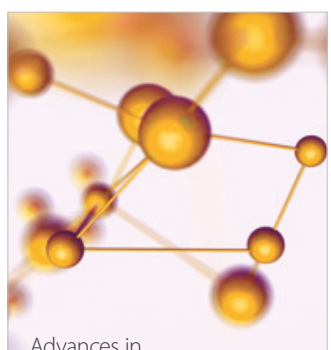

Physical Chemistry
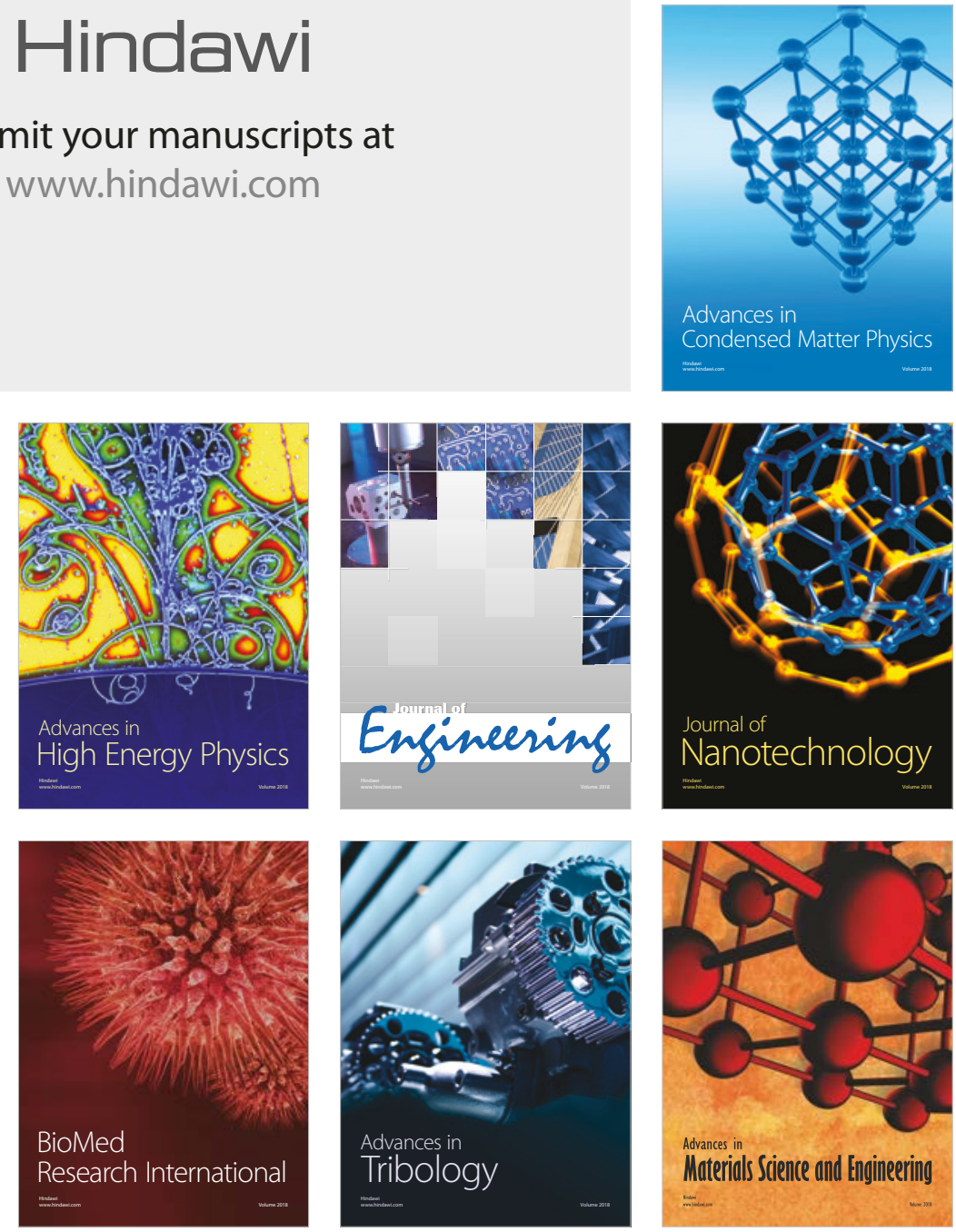